\section{$\$$ Research Square \\ Preprints are preliminary reports that have not undergone peer review. \\ They should not be considered conclusive, used to inform clinical practice, or referenced by the media as validated information.}

\title{
Psychometrics of The Physical Health Attitude Scale in Taiwanese Mental Health Nurses: A Validation Study Authors' Full Names
}

\author{
Wen-Chii Tzeng ( $\nabla$ wctzeng@mail.ndmctsgh.edu.tw) \\ National Defense Medical Center \\ Hsin-Pei Feng \\ Fu Jen Catholic University \\ Chia-Huei Lin \\ Tri-Service General Hospital \\ Yue-Cune Chang \\ Tamkang University \\ Mark Haddad \\ City University of London
}

\section{Research Article}

Keywords: attitude, instrument adaptation, nursing education, physical health care, validation studies

Posted Date: November 3rd, 2021

DOI: https://doi.org/10.21203/rs.3.rs-1033208/v1

License: (c) (i) This work is licensed under a Creative Commons Attribution 4.0 International License. Read Full License 


\section{Abstract \\ Background}

The Physical Health Attitude Scale (PHASe) is a reliable and valid scale for assessing mental health nurses' attitude towards providing physical healthcare to patients diagnosed with serious mental illness.

\section{Aims}

To psychometrically evaluate the Chinese adaptation of the PHASe.

\section{Methods}

A total of 520 mental health nurses from 11 hospitals across Taiwan participated in this study. Brislin's translation model was utilized for the validation process. Both exploratory factor analysis and confirmatory factor analysis were used to establish the construct validity of the scale, and Cronbach's alpha and composite reliability were used to determine reliability.

\section{Results}

The four-factor 17-item Chinese version of the PHASe demonstrated satisfactory fit with significant factor loadings. Each factor had adequate internal consistency (Cronbach's alpha $=0.70$ to 0.80 ). Known-group validity was supported by the significant differences between groups with different attitudes.

\section{Conclusions}

Our findings suggest that the Chinese version of PHASe is acceptable for evaluating nurses' attitude towards providing physical health care both within culturally Chinese societies and in cross-cultural studies.

\section{Introduction}

Compared with the general population, individuals with serious mental illness, such as schizophrenia, bipolar disorder, and major depressive disorder, have a higher risk of many physical health problems (such as cancers and metabolic, cardiovascular, viral, and respiratory tract diseases) globally (De Hert et al., 2011). The mortality rate in patients diagnosed with serious mental illness has been reported to be two- to three-fold higher than that of the general population (Walker, McGee, \& Druss, 2015), and the life expectancy of these individuals is approximately 15 years less than that of the general population (Hjorthøj, Stürup, McGrath, \& Nordentoft, 2017). In Taiwan, compared with the general population, serious mental illness is associated with higher mortality and healthcare expenditure (Wang, Chang, Lee, \& Li, 2020), and this gap appears to be increasing between patients diagnosed with serious mental illness and the general population (Pan, Yeh, Chan, \& Chang, 2017). Apparently, patients diagnosed with serious mental illness are not benefiting from advances in healthcare. Because nurses working in the mental healthcare system play an essential role, increasing their abilities to provide the required physical healthcare and implement early interventions is crucial. Despite the growing awareness of comorbid physical and mental diseases, no valid scale for measuring mental health nurses' attitude towards physical healthcare has been developed for culturally Chinese societies.

\section{Background}

Serious mental illness is a mental, behavioural, or emotional disorder that substantially interferes with an individual's life activities, such as their interpersonal relationships, daily living activities, self-care, employment, and recreation (National Institute of Mental Health, 2017). Evidence is accumulating that multiple factors, such as genetic predisposition, psychiatric symptoms, responsiveness to antipsychotic medication, and willingness to make lifestyle changes (such as tobacco cessation, regular physical activity, and healthy diet), negatively influence the physical health of patients diagnosed with serious mental illness (de Mooij et al., 2019). Unfortunately, these factors interact with patients' disadvantaged social and economic environment as well as psychosocial stressors and risk behaviours, such as substance use and suicidal or violent behaviours. Thus, nurses must have the necessary skills to motivate and support patients diagnosed with serious mental illness to improve their physical health.

Healthcare disparities across the health care continuum of screening, diagnosis, treatment, and end-of-life care are influenced by the pervasive stigma of mental illness (Major, Dovidio, \& Link, 2018). The stigma of mental illness also affects the interaction between patients and health care professionals, who can not only view patients diagnosed with serious mental illness as difficult but also face challenges in diagnosing and treating medical disease in such patients, especially when patients exhibit bizarre affect, violent behaviour, or poor health literacy (Giandinoto \& Edward, 2014). A study conducted in Taiwan reported that patients diagnosed with schizophrenia had a 1.3- to 1.8-fold increased risk of an adverse clinical event (such as intensive care unit admission, acute respiratory failure, or mechanical ventilation use) during medical and surgical hospitalisations compared with those without schizophrenia (Chen, Lin, \& Lin, 2011). Therefore, increased awareness of health disparities and understanding by mental health nurses of the barriers to physical health care in patients diagnosed with serious mental illness are essential. 
Historically, mental health nurses have focused on providing care to improve patients' mental health, but they perceive that they have inadequate physical healthcare knowledge and skills and lack confidence in delivering physical healthcare (Happell, Platania-Phung, \& Scott, 2014). Gray and Brown (2017) interviewed 18 Australian mental health nurses and 15 patients diagnosed with serious mental illness regarding their experiences of working together to improve physical health. That study identified that the nurses did not give high priority to improving patients' physical health, and the patients reported that their physical health needs were not adequately addressed. Thus, the attitude of mental health nurses is a matter of concern because these nurses have the potential to negatively influence the detection and management of comorbid mental and medical diseases.

Price (2015) defined attitudes as an individual's disposition to react to certain situations based on the beliefs and experiences that influence the individual's behaviour. Price further argued that attitude is agreed to be evaluated as either positive or negative in health care despite the various conceptions of attitude proposed by different theorists. Attitude is developed within an individual's mind and cannot always be clearly defined. However, attitude constructs are considered to comprise three components: affection, cognition, and behaviour (known as the ABC model of attitude) (Eagly \& Chaiken, 1993).

Robson and Haddad (2012) developed a validated measurement tool, namely the Physical Health Attitude Scale (PHASe), to measure mental health nurses' attitude toward providing physical health care to patients diagnosed with serious mental illness. This scale is viewed within the context of the ABC model of attitude. The psychometric properties of the PHASe in various languages have been tested, including Arabic (Ganiah, Al-Hussami, \& Alhadidi, 2017), Japanese (Bressington et al., 2018), and Turkish (Ozaslan, Bilgin, Uysal Yalcin, \& Haddad, 2020), and studies using this instrument have enabled some international comparisons of nurse attitude (e.g., Australia, Canada, Hong Kong, Qatar, the United States, and the United Kingdom) (Dickens, lon, Waters, Atlantis, \& Everett, 2019). Although using such a validated scale to assess mental health nurses' attitude toward providing physical healthcare can help nurse educators identify factors associated with their attitude, the PHASe is not available in the Chinese language. This paper presents the cultural adaptation of the PHASe, and the psychometric properties of the Chinese version of the PHASe were also determined.

\section{Methods}

\section{Design and participants}

A descriptive, cross-sectional study was conducted using data collected between August and December 2019. Participants were recruited from 11 hospitals across Taiwan-five mental health hospitals, five regional hospitals, and one medical centre. The medical centre had 200 psychiatric inpatient beds, and each of the five regional hospitals had more than 50 psychiatric inpatient beds. The inclusion criteria were as follows: (1) full-time direct care registered nurse, (2) aged 20 years or older, and (c) at least 1 year of psychiatric mental health nursing practice. Nurse leaders-including head nurses, supervisors, and directors of the nursing department-were excluded.

The minimum sample size for factor analysis is a 10:1 ratio of the number of cases to the number of items (Hair, 2010). The PHASe comprises 28 items; thus, the minimum sample size was 280 . In total, 835 nurses were evaluated, 669 satisfied the eligibility criteria, and 620 expressed their interest in participation. Among 547 returning questionnaires (88.2\%), 27 were incomplete ( 2 nurses did not complete any of the questionnaires and 25 had not completed the PHASe). Analysis of data from complete and incomplete respondents revealed no significant selection bias in demographic and job-related variables. The valid response rate was $83.9 \%(n=520$; attrition rate $=16.1 \%)$ after eliminating the 27 incomplete responses. According to the Ministry of Health and Welfare, Taiwan (2021), the number of mental health nurses was 5,554 in 2019. This study recruited 520 nurses, who thus accounted for $9.3 \%$ of the mental health nurses in Taiwan.

\section{Data collection}

Approval to perform this study was obtained from the institutional review board of the principal investigator's medical centre (Reference No. 1-108-05-092). We met the eligible nurses during their break time to introduce the purpose of the study and subsequently invited them to join after obtaining approval from the head of the nursing department of each hospital. Eligible nurses also received an information sheet outlining the study aims and the procedures for protecting confidentiality. All participants provided written consent prior to data collection. Their participation was voluntary and anonymous. All questionnaires were returned in sealed envelopes to the principal investigator.

\section{Measures: PHASe}

Data were collected using an anonymous form that comprised a demographic data form and the Chinese version of the PHASe. The demographic data collected were age, gender, educational background, nursing experience, and other related demographic variables were collected.

The PHASe is a 28-item instrument, and each item is scored on a 5-point Likert scale (ranging from 1 [strongly disagree] to 5 [strongly agree]) (Robson \& Haddad, 2012). The PHASe has 12 negatively worded items, and its total score ranges from 28 to 140 . A higher score indicates a more positive attitude. The Cronbach's alpha for the total scale was 0.76 , and the Cronbach's alpha values for the four subscales were: attitude toward involvement in physical healthcare $(0.86$, ten items), confidence in delivering physical health care $(0.74$, six items), perceived barriers to physical health care delivery $(0.67$, seven items), and attitude to smoking (0.61, five items) (Robson \& Haddad, 2012).

Brislin's translation model was used to guide the translation and validation of the PHASe (Jones, Lee, Phillips, Zhang, \& Jaceldo, 2001). After we obtained the authorisation of the two original authors (Robson \& Haddad, 2012), two research members who were proficient in English and Chinese and had experience in translating scholarly nursing-related writing first translated the scale to Chinese. The first Chinese version was then back-translated into English by a professional translation company that had not participated in the first translation work or seen the original English version. After ensuring the 
congruence of culturally equivalent meanings between the two versions, the final back-translated version was sent to Dr Haddad through e-mail to determine whether the back-translated version is identical to the original version. This process was repeated until the back-translated items and originals conveyed the same meaning.

Five experts (two clinical nurses with a master's degree in nursing, one doctoral nursing student, and two nurse academics) with experience in working with patients diagnosed with serious mental illness were invited to rate the Chinese version of the PHASe by using a 4-point Likert scale to score each item for determining the cultural equivalence, relevance, and appropriateness of this scale. Items with a mean score of $\geq 3.0$ were retained (Polit \& Beck, 2018 ). The average item-level content validity index for all items was 0.98 . No items were deleted from the Chinese version. The final version was obtained after the elimination of redundant wording and adjectives on the basis of the panel's recommendations.

\section{Analysis}

Data were managed and analysed using SPSS (version 20.0, SPSS Inc., Chicago, IL, USA) and Amos (version 18, SPSS Inc.), with significance set at 0.05. Demographic data are described using $n(\%)$ for categorical variables and the mean (standard deviation [SD]) for continuous variables.

Construct validity was examined using exploratory factor analysis (EFA), confirmatory factor analysis (CFA), and known-group validity. An EFA conducted using the maximum likelihood method and oblique rotation was used to explore the factor structure of the Chinese version of the PHASe (Nunnally \& Bernstein, 1994). The factors were retained if they had eigenvalues of $>1.0$ (indicating that the factor explained more of the total variance than a single item included in the analysis), assessed using a scree plot. Items with factor loadings of $<0.5$ or with cross-loading were excluded (DeVellis, 2017).

CFA was performed using the maximum likelihood estimation with structural equation modelling to test how the data-driven structure obtained from the EFA was adapted to Taiwanese cultural conditions. The model fit of the proposed model was assessed using the root-mean-square error of approximation (RMSEA), the standardised root-mean-square residual (SRMR), the comparative fit index (CFI), and the Tucker-Lewis index (TLI). A satisfactory model fit was defined as RMSEA of $<0.08$, SRMR of $\leq 0.06$, CFI of $\geq 0.95$, and TLI of $\geq 0.95$ (Hu \& Bentler, 1999). Values of the standardised factor loadings of each item (measured variable) on the corresponding factor (latent construct) were $>0.5$, and statistical significance were expected. The relationships between factors were examined with a correlation coefficient of $<0.7$ (Prudon, 2015).

Known-group validity was used to determine whether the Chinese version of the PHASe could discriminate between groups with different attitudes (Polit \& Beck, 2018). Based on the findings by Robson et al. (2013), nurses with male gender, nonsmoking status, bachelor's degree or higher education level, adult care experience, and physical health care training were hypothesized to have higher total PHASe scores on the four subscale scores. The mean total scores and four subscales of the predefined groups were compared using independent $t$-tests, and the magnitude of the difference was measured as the effect size (Cohen's d), which was calculated as the mean difference between two groups divided by the pooled standard deviation. Cohen (1988) classified effect sizes as follows: small effect $(d=0.2)$, moderate effect $(d=0.5)$, and large effect $(d=0.8)$.

Internal consistency was assessed by Cronbach's alpha coefficient. Results with Cronbach's alpha $\geq 0.7$ were regarded acceptable reliability (Polit \& Beck, 2018). Composite reliability (CR) was used to measure the internal consistency of a set of items within a latent construct. A CR of $\geq 0.7$ indicated that items belonging to the same factor were highly correlated and that no items were unreliable (Hair, 2010).

\section{Results \\ Participant}

The demographic characteristics are presented in Table 1. The mean age was $36.7(S D=8.95)$ years. The majority of the nurses were female (91.7\%), were working in mental health hospitals (66.7\%), and had at least a bachelor's degree in nursing (64.0\%). The respondents had worked as mental health nurses for 1-32 years, with a mean experience of 9.23 years. Although $50.4 \%(n=262)$ had adult care experience, only $74(14.2 \%)$ participants had attended inservice physical healthcare training within the preceding five years. 
Table 1

Participant demographics $(n=520)$

\begin{tabular}{|c|c|c|c|c|c|}
\hline Variable & $\mathbf{n}$ & $\%$ & Mean & SD & Range \\
\hline Age (years old) & & & 36.70 & 8.95 & $21-62$ \\
\hline$<40$ & 317 & 61.0 & & & \\
\hline$\geq 40$ & 203 & 39.0 & & & \\
\hline \multicolumn{6}{|l|}{ Gender } \\
\hline Men & 43 & 8.3 & & & \\
\hline Women & 477 & 91.7 & & & \\
\hline \multicolumn{6}{|l|}{ Level of education } \\
\hline Associate degree & 187 & 36.0 & & & \\
\hline$\geq$ Bachelor of Science degree & 333 & 64.0 & & & \\
\hline \multicolumn{6}{|l|}{ Smoking } \\
\hline Current/ formerly & 15 & 2.9 & & & \\
\hline Never & 505 & 97.1 & & & \\
\hline \multicolumn{6}{|l|}{ Hospital type } \\
\hline Mental health hospital & 347 & 66.7 & & & \\
\hline General hospital & 173 & 33.3 & & & \\
\hline \multicolumn{6}{|l|}{ Work unit } \\
\hline Acute psychiatric ward & 304 & 58.5 & & & \\
\hline Other & 216 & 41.5 & & & \\
\hline \multicolumn{6}{|l|}{ Nursing background } \\
\hline Years of mental health nursing practice & & & 9.23 & 6.93 & $1-32$ \\
\hline$<15$ & 403 & 77.5 & & & \\
\hline$\geq 15$ & 117 & 22.5 & & & \\
\hline \multicolumn{6}{|l|}{ Adult care experience } \\
\hline Yes & 262 & 50.4 & & & \\
\hline No & 258 & 49.6 & & & \\
\hline \multicolumn{6}{|c|}{ Attended physical health care training programme } \\
\hline Yes & 74 & 14.2 & & & \\
\hline No & 446 & 85.8 & & & \\
\hline
\end{tabular}

\section{Exploratory factor analysis}

An EFA using the maximum likelihood method and oblique rotation was performed, and the initial seven factors extracted accounted for $41.57 \%$ of the total variance. However, seven items $(4,5,11,13,23,27$, and 28$)$ were excluded because their factor loadings were $<0.5$, and one item $(20)$ was crossloaded. EFA was then conducted on the remaining 20 items, and five factors were extracted accounting for $42.99 \%$ of the total variance. Three items (8, 14 , and 24) were also removed because they had factor loadings of $<0.5$. Of the remaining 17 items, two factors (2 and 5$)$ did not include at least 3 items.

We then performed a model comparison on the factor models with three- and four-factor structures. While all six items belonging to the subscale 'confidence in delivering physical healthcare' of the original PHASe (Robson \& Haddad, 2012) were excluded because their factor loadings were <0.5 in the three-factor structure, the remaining 17 items were loaded on the factors corresponding to those of the original PHASe in the four-factor structure (Table 2). Factor 1 (involvement in physical healthcare, six items) accounted for $19.8 \%$ of the total variance. Factor 2 (attitude to smoking, four items) accounted for $10.4 \%$ of the total variance. Factor 3 (perception of obstacles to engagement in physical healthcare, three items) accounted for $8.2 \%$ of the total variance. Finally, factor 4 (confidence in physical healthcare practice, six items) accounted for $5.7 \%$ of the total variance. 


\begin{tabular}{|c|c|c|c|c|c|}
\hline No. & Statement & $\begin{array}{l}\text { Factor } \\
1^{\dagger}\end{array}$ & $\begin{array}{l}\text { Factor } \\
2^{\dagger}\end{array}$ & $\begin{array}{l}\text { Factor } \\
3^{\dagger}\end{array}$ & $\begin{array}{l}\text { Factor } \\
4^{\dagger}\end{array}$ \\
\hline 22 & $\begin{array}{l}\text { Ensuring that patients have their eyes regularly assessed by an optician should be part of the mental } \\
\text { health nurses' role }\end{array}$ & 0.745 & & & \\
\hline 10 & Ensuring that patients are registered with a dentist should be part of the mental health nurses' role & 0.736 & & & \\
\hline 25 & Mental health nurse should educate male patients on the importance of testicular self-examination & 0.681 & & & \\
\hline 17 & Mental health nurses should educate female patients on the importance of breast self-examination & 0.646 & & & \\
\hline 7 & $\begin{array}{l}\text { Verifying that patients have had cancer screenings (i.e. cervical smear/mammogram) should not be part } \\
\text { of the mental health nurse's role. }\end{array}$ & 0.583 & & & \\
\hline 6 & Advising on heart disease prevention should be part of the mental health nurses' role & 0.538 & & & \\
\hline 20 & Patients should be banned from smoking on all Healthcare premises & & 0.886 & & \\
\hline 16 & Patients should be given cigarettes to help achieve therapeutic goals & & 0.624 & & \\
\hline 14 & Staff should be banned from smoking on all Healthcare premises & & 0.579 & & \\
\hline 12 & Patients should not be encouraged to give up smoking, because they have enough to cope with & & 0.534 & & \\
\hline 18 & Encouraging patients to follow healthy-eating advice is difficult & & & 0.780 & \\
\hline 9 & It is difficult to get clients to follow advice on how to manage their weight & & & 0.714 & \\
\hline 15 & Patients are not motivated to exercise & & & 0.532 & \\
\hline 19 & I am confident in assessing signs and symptoms of hypoglycemia & & & & 0.701 \\
\hline 3 & I am confident in assessing signs and symptoms of hyperglycemia & & & & 0.663 \\
\hline 26 & I am confident that I could resuscitate a patient with cardiac arrest & & & & 0.543 \\
\hline 21 & I am confident that I know which psychotropic drugs increase the risk of cardiac problems & & & & 0.543 \\
\hline \multicolumn{2}{|c|}{ Eigenvalue } & 4.174 & 2.067 & 1.926 & 1.449 \\
\hline \multicolumn{2}{|c|}{ Variance explained (\%) } & $19.8 \%$ & $10.3 \%$ & $8.2 \%$ & $5.7 \%$ \\
\hline \multicolumn{2}{|c|}{ Cronbach's alpha } & 0.81 & 0.75 & 0.70 & 0.70 \\
\hline \multicolumn{2}{|c|}{ Composite reliability } & 0.80 & 0.74 & 0.72 & 0.70 \\
\hline
\end{tabular}

\section{Confirmatory factor analysis}

Two models were tested to validate the conceptual structure of the Chinese version of the PHASe. Model 1 retained 28 items with the four-factor structure obtained by Robson and Haddad (2012), and model 2 was based on EFA results of four-structure 17 items. As shown in Table 3 , model 2 fitted the data better and the model fit indices were $\chi^{2}=199.58, d f=102$, RMSEA $=0.04$, SRMR $=0.04, \mathrm{CFI}=0.96$, and TLI $=0.95$. All items of the Chinese version of PHASe loaded significantly on their corresponding factors with a range of $0.45-0.95$. The correlations among the four factors in the Chinese version of PHASe ranged from 0.10 to 0.41 (Figure 1). Therefore, the results demonstrated that the four-factor structure with 17 items was satisfactory for the Chinese version of the PHASe. 
Table 3

Selected indices for comparing different models of the Chinese version of PHASe

\begin{tabular}{|c|c|c|c|}
\hline Index & Evaluation standard & Model $1^{\dagger}$ & Model $2^{\dagger}$ \\
\hline$x^{2}$ & - & 1046.32 & 199.58 \\
\hline$d f$ & - & 344 & 102 \\
\hline RMSEA $^{\ddagger}$ & $<0.08$ & 0.06 & 0.04 \\
\hline SRMR $^{\ddagger}$ & $\leq 0.06$ & 0.05 & 0.04 \\
\hline $\mathrm{CFI}^{\ddagger}$ & $\geq 0.95$ & 0.81 & 0.96 \\
\hline $\mathrm{TLI}^{\ddagger}$ & $\geq 0.95$ & 0.79 & 0.95 \\
\hline
\end{tabular}

${ }^{\dagger}$ Model 1 = theoretically driven four-factor structure with 28 items, and Model 2 = empirically derived four-factor structure with 17 items.

${ }^{\ddagger} \mathrm{RMSEA}=$ root-mean-square error of approximation, SRMR = standardised root-mean-square residual, CFI = comparative fit index, and TLI = TuckerLewis index.

\section{Reliability}

Cronbach's alpha coefficient was used to assess the internal consistency reliability of the total scale and subscales. Cronbach's alpha coefficient for the final 17-item Chinese version of the PHASe was 0.80 , and the values for its subscales $1,2,3$, and 4 were $0.82,0.75,0.70$, and 0.70 , respectively (Table 2 ). The composite reliability values for the four subscales ranged from 0.70 to 0.80 , indicating that items belonging to the same subscales were correlated.

\section{Known-group validity}

As displayed in Table 4, the mean total PHASe score was significantly higher among those with a nonsmoking status $(t=2.05, p=0.041)$, adult care experience $(t=2.23, p=0.026)$, and physical healthcare training $(t=2.51, p=0.012)$. The mean 'attitude to involvement in physical healthcare' score was significantly higher in nonsmokers $(t=2.07, p=0.038)$. The mean 'attitude to smoking' score differed based on gender $(t=-2.61, p=0.009)$ and adult care experience $(t=3.55, p<0.001)$. The mean 'confidence in physical healthcare practice' score was positively associated with adult care experience $(t=5.30$, $p<0.001)$ and physical healthcare training $(t=3.40, p=0.001)$. No group differences were observed in the mean 'perception of obstacles to engagement in physical healthcare' score. 
Table 4

Comparison of scores overall and for each of the four subscales of the Chinese version of the PHASe by demographics $(n=520)$

\begin{tabular}{|c|c|c|c|c|c|c|c|c|c|c|c|c|c|c|c|}
\hline \multirow[t]{2}{*}{ Variable } & \multicolumn{3}{|c|}{ Factor $1^{\dagger}$} & \multicolumn{3}{|c|}{ Factor $2^{\dagger}$} & \multicolumn{3}{|c|}{ Factor $3^{\dagger}$} & \multicolumn{3}{|c|}{ Factor $4^{\dagger}$} & \multicolumn{3}{|c|}{ Total Score } \\
\hline & $\begin{array}{l}\text { mean } \\
(\mathrm{SD})\end{array}$ & $P$ & $\mathrm{ES}^{\ddagger}$ & $\begin{array}{l}\text { mean } \\
(\mathrm{SD})\end{array}$ & $P$ & $\mathrm{ES}^{\ddagger}$ & $\begin{array}{l}\text { mean } \\
(\mathrm{SD})\end{array}$ & $P$ & $\mathrm{ES}^{\ddagger}$ & $\begin{array}{l}\text { mean } \\
(\mathrm{SD})\end{array}$ & $P$ & $\mathrm{ES}^{\ddagger}$ & $\begin{array}{l}\text { mean } \\
(S D)\end{array}$ & $P$ & $\mathrm{ES}^{\ddagger}$ \\
\hline \multicolumn{16}{|l|}{ Gender } \\
\hline \multirow{2}{*}{$\begin{array}{l}\text { Men }(n \\
=43)\end{array}$} & 19.56 & 0.476 & 0.11 & 15.07 & 0.009 & 0.38 & 6.47 & 0.081 & 0.28 & 15.33 & 0.749 & 0.05 & 56.42 & 0.218 & 0.18 \\
\hline & $(4.171)$ & & & (3.487) & & & (2.164) & & & (1.899) & & & (8.438) & & \\
\hline \multirow{2}{*}{$\begin{array}{l}\text { Women }(n \\
=477)\end{array}$} & 19.09 & & & 16.27 & & & 7.08 & & & 15.42 & & & 57.86 & & \\
\hline & $(4.162)$ & & & (2.837) & & & (2.196) & & & (1.879) & & & (7.210) & & \\
\hline \multicolumn{16}{|l|}{$\begin{array}{l}\text { Level of } \\
\text { education }\end{array}$} \\
\hline \multirow{2}{*}{$\begin{array}{l}\text { Associate } \\
\text { degree }(n \\
=187)\end{array}$} & 18.65 & 0.052 & 0.18 & 15.85 & 0.058 & 0.17 & 7.02 & 0.978 & 0.00 & 15.41 & 0.988 & 0.00 & 56.94 & 0.052 & 0.17 \\
\hline & (3.875) & & & (2.778) & & & $(2.130)$ & & & (1.982) & & & $(6.645)$ & & \\
\hline \multirow{2}{*}{$\begin{array}{l}\geq \text { BS§ } \\
\text { degree }(n \\
=333)\end{array}$} & 19.39 & & & 16.35 & & & 7.03 & & & 15.41 & & & 58.19 & & \\
\hline & $(4.295)$ & & & (2.972) & & & (2.238) & & & (1.684) & & & (7.647) & & \\
\hline \multicolumn{16}{|l|}{ Smoking } \\
\hline \multirow{2}{*}{$\begin{array}{l}\text { Currently/ } \\
\text { formerly } \\
(n=15)\end{array}$} & 16.93 & 0.038 & 0.55 & 15.07 & 0.286 & 0.33 & 6.73 & 0.602 & 0.15 & 15.20 & 0.656 & 0.12 & 53.93 & 0.041 & 0.51 \\
\hline & $(4.061)$ & & & (3.955) & & & (1.831) & & & (1.781) & & & (8.102) & & \\
\hline \multirow{2}{*}{$\begin{array}{l}\text { Never }(n= \\
505)\end{array}$} & 19.19 & & & 16.21 & & & 7.03 & & & 15.42 & & & 57.85 & & \\
\hline & $(4.149)$ & & & (2.873) & & & (2.209) & & & (1.883) & & & (7.274) & & \\
\hline \multicolumn{16}{|l|}{$\begin{array}{l}\text { Adult care } \\
\text { experience }\end{array}$} \\
\hline \multirow{2}{*}{$\begin{array}{l}\text { Yes }(n= \\
262)\end{array}$} & 18.92 & 0.267 & 0.10 & 16.62 & $<0.001$ & 0.31 & 7.06 & 0.677 & 0.04 & 15.84 & $<0.001$ & 0.47 & 58.44 & 0.026 & 0.20 \\
\hline & (4.122) & & & $(2.465)$ & & & (2.158) & & & (1.764) & & & (6.945) & & \\
\hline \multirow{2}{*}{$\begin{array}{l}\text { No }(n= \\
258)\end{array}$} & 19.33 & & & 15.72 & & & 6.98 & & & 14.98 & & & 57.02 & & \\
\hline & (4.197) & & & (3.246) & & & $(2.240)$ & & & (1.898) & & & (7.630) & & \\
\hline \multicolumn{16}{|l|}{$\begin{array}{l}\text { Prior } \\
\text { physical } \\
\text { healthcare } \\
\text { training }\end{array}$} \\
\hline \multirow{2}{*}{$\begin{array}{l}\text { Yes }(n= \\
74)\end{array}$} & 19.91 & 0.081 & 0.22 & 16.53 & 0.259 & 0.14 & 7.18 & 0.525 & 0.08 & 16.09 & 0.001 & 0.43 & 59.70 & 0.012 & 0.31 \\
\hline & $(4.317)$ & & & $(2.873)$ & & & (2.278) & & & (1.830) & & & (7.851) & & \\
\hline \multirow{2}{*}{$\begin{array}{l}\text { No }(n= \\
446)\end{array}$} & 19.00 & & & 16.11 & & & 7.00 & & & 15.30 & & & 57.41 & & \\
\hline & $(4.124)$ & & & (2.917) & & & (2.186) & & & (1.865) & & & (7.186) & & \\
\hline \multicolumn{16}{|c|}{$\begin{array}{l}{ }^{\dagger} \text { Factor } 1=\text { Involvement in physical healthcare (six items), Factor } 2=\text { Attitude to smoking (four items), Factor } 3=\text { Perception of obstacles to } \\
\text { engagement in physical healthcare (three items), and Factor } 4 \text { = Confidence in physical healthcare practice (six items). }\end{array}$} \\
\hline \multicolumn{16}{|c|}{${ }^{\ddagger} \mathrm{ES}=$ effect size } \\
\hline$\S_{\mathrm{BS}}=\mathrm{Bach}$ & of Scie & & & & & & & & & & & & & & \\
\hline
\end{tabular}


The effect sizes of the relationships of smoking with total score and 'involvement in physical healthcare' were moderate ( 0.51 and 0.55 , respectively). The effect size of the relationship between gender and 'attitude to smoking' was low (0.38). The effect sizes of the relationships of adult care experience with total score, 'attitude to smoking,' and 'confidence in physical healthcare practice' were low $(0.20,0.31$, and 0.47 , respectively). The effect sizes of the relationships of prior physical healthcare training with total score and 'confidence in physical healthcare practice' were low ( 0.31 and 0.43 , respectively).

\section{Discussion}

In the present study, a sample of 520 mental health nurses was used to evaluate a cross-cultural Chinese adaptation of the PHASe. Initially, factor analysis yielded a scale with a seven-factor structure, which was substantially different from the original four-factor structure (Robson \& Haddad, 2012). However, the main aim of this study was to develop a Chinese version of the PHASe for use in studies comparing mental health nurses' attitudes towards physical healthcare across samples. After EFA was performed with the forced extraction of four factors with an eigenvalue of $>1$ and factor loading of $>0.5,17$ items were loaded on the corresponding factors of the original PHASe. Furthermore, CFA results supported the four-factor, 17-item Chinese version of the PHASe.

EFA on our data confirmed the validity of the four-factor structure of the PHASe, which is similar to the structure of the original instrument. However, 11 items were removed in the Chinese version. The original version of the PHASe, developed in the United Kingdom, comprises 28 items, whereas the Canadian, Turkish, and Chinese versions comprise 15, 24, and 17 items, respectively. Siren et al. (2018) obtained a two-factor model for the Canadian version; the components of involvement and perceived barriers were combined, whereas the smoking component was removed. Ozaslan et al. (2020) obtained a four-factor model for their Turkish version of the PHASe; however, some items were loaded on different factors, and the name of factor 4 was changed because it combined two domains (attitudes to smoking and negative beliefs). These differences may be because mental health nurses in different cultures perceive their role in providing physical healthcare from differing perspectives.

The variance explained by the four-factor model in this study was relatively low (44.2\%); however, this finding was consistent with the variance explained by the original version of the PHASe developed in the United Kingdom (42.1\%) (Robson \& Haddad, 2012) and the validated Canadian (46.8\%) (Siren et al., 2018) and Turkish (51.3\%) (Ozaslan et al., 2020) versions of the PHASe. These relatively low total variances in the Chinese versions of PHASe suggest that mental health nurses are a relatively homogeneous group, which restricts the range in the measures when performing EFA (Fabrigar et al., 1999). Mental health nurses in Taiwan implement nursing care following the national hospital accreditation standards. The consistent physical health care provision may result in a low total variance.

Both RMSEA and SRMR values supported the 4-factor 17-item Chinese version of the PHASe. Furthermore, each factor consisted of at least three items. All items were loaded on the same corresponding factors as those in the original PHASe (Robson \& Haddad, 2012). The intercorrelation results among four factors also achieved the required discriminant validity, indicating that each factor reflected a specific subscale of the Chinese version of the PHASe. Therefore, the Chinese version of the PHASe with four factors and 17 items displayed suitable construct validity.

'Involvement in physical healthcare' was determined to be the factor accounting for the highest percentage (19.8\%) of variance. This factor also accounted for the highest percentage of variance in the original version of the PHASe (15.5\%) (Robson \& Haddad, 2012) and the Turkish version of the PHASe (23.1\%) (Ozaslan et al., 2020). However, item 1 ("Helping patients control their weight is a responsibility of psychiatric nurses"), item 2 ("Psychiatric nurses should be responsible for providing nutrition advice to patients"), item 4 ("Psychiatric nurses should not provide exercise-related advice to patients"), and item 11 ("Psychiatric nurses should provide contraception advice to patients") were removed from the aforementioned factor in the Chinese version of the PHASe because of low factor loadings (<0.5) in EFA, which is consistent with the findings for the Canadian version (Siren et al., 2018). In the Turkish version, item 1 displayed cross-loading on both "Nurses' attitudes to involvement in physical health care" and "Nurses' confidence in delivering physical health care," and item 4 was removed from the PHASe (Ozaslan et al., 2020). Chee et al. (2018) reported no group difference in both items between generalist-prepared nurses and mental-health nurses in Australia. This finding may be because the PHASe was developed before the World Health Organization's global recommendations regarding the minimum frequency, duration, intensity, type, and total amount of physical activity required for health (World Health Organization, 2010). Nurses have become aware of the importance of physical activity for noncommunicable disease prevention over the past decade. Therefore, these four items do not have sufficient discriminatory power to evaluate nurses' attitude toward physical healthcare despite being a crucial contributor. This finding requires further investigation in future studies.

Our results demonstrated that factor 2 (attitude to smoke) was comparable with factor 4 of the original PHASe. Taiwan implemented the Tobacco Hazards Prevention Act in 2009 (Health Promotion Administration, 2019). Over the past decade, all hospitals have become smoke-free environments, and all hospital staff members are required to support the tobacco-free policy, and they have received training to provide smoking-cessation services. The majority of nurses in our study reported not using tobacco in any form. However, a study conducted in Taiwan revealed that mental health nurses had low selfefficacy and practical experience in providing smoking-cessation services for patients diagnosed with serious mental illness (Guo, Wang, \& Shu, 2015). Therefore, four of the five items were retained to assess nurses' attitude toward patients' smoking cessation.

Four items, item 5 ("Patients with severe psychiatric problems are uninterested in improving their physical health"), item 13 ("Informing patients of the potential effects of medications on their physical health can increase their noncompliance"), item 23 ("My workload restricts me from administering any health-promotion measures to patients"), and item 27 ("Patients are worried about their physical health mostly because of their mental illness") were removed from the 'perception of obstacles to engagement in physical healthcare' factor of the Chinese version of the PHASe, which is similar to the findings (items 13, 23, 27) of the Canadian version of PHASe (Siren et al., 2018). In the Turkish version, both items 13 and 27 were loaded in the "attitudes to smoking and negative beliefs" factor (Ozaslan et al., 2020). These results were not surprising because technology plays a crucial role in health

Page 9/13 
education for patients diagnosed with serious mental illness. In addition, mental health nurses in Taiwan have used health information systems to perform and document health education based on patients' health needs (Tseng, Liou, \& Chiu, 2012).

The known-group validity was assessed, and four of the five hypotheses displayed moderate to small effect sizes, which indicated that the Chinese version of the PHASe and its subscales could discriminate between groups defined using high versus low characteristics affecting mental health nurses' attitude. However, no significant differences were observed in the mean score of the 'perception of obstacles to engagement in physical healthcare' factor for nurses with differing personal and nursing backgrounds. A plausible explanation for this result is that all the items in this domain were negatively phrased items, which could have caused confusion in the participants because one negative phrase can have two types of inferences in Chinese (Chen, Huang, \& Politzer-Ahles, 2018). Another possible reason is that the training of mental health nurses in Taiwan follows a system similar to that in the United States and Australia, where nurses qualify as registered nurses before choosing to specialise in mental health, whereas in the United Kingdom, nurses choose to specialise in mental health from the outset of their undergraduate programme and qualify as registered psychiatric nurses. Compared with the sample in the study by Robson et al. (2013), much more nurses with adult nursing care experience participating in our validation study perceived that they have experienced physical health care knowledge and skills. Nevertheless, although the known-group comparison hypothesis of perceived barriers was rejected, our finding provides evidence that nurses in Taiwan perceive the same levels of barriers.

Regarding reliability, the 17-item Chinese version of the PHASe had satisfactory internal consistency, with Cronbach's a $=0.80$ for the entire scale, is comparable to that of the original version (0.77) (Robson \& Haddad, 2012) and a Turkish version (0.83) (Ozaslan et al., 2020). The reliability of the four subscales ranged from 0.70 to 0.80 , which is comparable to the reliability obtained for samples of mental health nurses in the United Kingdom ( $0.61-$ 0.86) (Robson \& Haddad, 2012), Australia (0.60-0.83) (Chee et al., 2018), Hong Kong (0.66-0.85), Japan (0.65-0.76), and Qatar (0.36-0.77) (Bressington et al., 2018), and Turkish (0.64-0.88) (Ozaslan et al., 2020). The aforementioned results reveal that the Chinese version of the PHASe reliably assesses mental health nurses' attitude toward physical health care.

This adaptation was performed on a sufficient sample size of mental health nurses from diverse nursing backgrounds. Therefore, the 4-factor structure of the Chinese version may be useful for future studies of culturally Chinese societies. Moreover, the Chinese version only comprises 17 items, which is practical for measuring mental health nurses' attitudes toward physical healthcare. However, a model with different factors may be useful for improving the variability explained by the model in light of the low total variance in the 4-factor structure. The adaptation of the Chinese version of the PHASe should be further investigated using multiple analyses to test its validity and reliability; relevant parameters include convergent validity, criterion validity, and testretest reliability.

Another limitation of this study is the limited generalisability of the findings. Although multisetting sampling was used to obtain adequate sample size, the results cannot be generalised to all mental health nurses because this study recruited nurses working in hospitals. Most of the participants were female and worked in acute inpatient psychiatric wards, which limits the generalisability of the results. To improve the generalisability of the results, additional cross-validated studies should be conducted using a diverse sample of nurses for confirming the four-factor structure of the Chinese version of the PHASe. Moreover, the data were obtained using self-report methods; thus, bias may occur in the results. Future research is needed to clarify the psychometric properties of the Chinese version developed in the current study.

\title{
Conclusion
}

The present study validated the translation by theoretically and empirically testing the measures of mental health nurses' attitude toward the provision of physical health care for people diagnosed with serious mental illness. The reliability and validity of the 4-factor, 17-item Chinese version of the PHASe are comparable with those of the original English version. The Chinese version of the PHASe could thus be used to evaluate the attitude of mental health nurses toward physical health care, both within culturally-Chinese societies and in cross-cultural studies using the PHASe in several languages. Furthermore, the finding of this study could be employed by nurse educators to develop appropriate physical health training programs for mental health nurses to improve the management of the comorbid mental and chronic diseases of patients.

\section{Relevance To Clinical Practice}

The current findings suggest the four-factor, 17-item Chinese version of the PHASe was empirically and theoretically supported to assess mental health nurses' attitude towards providing physical healthcare both within culturally Chinese societies and in cross-cultural studies. Additionally, it helps nurse educators to develop appropriate educational programmes to enhance mental health nurses' abilities to manage comorbid mental and chronic diseases.

\section{List Of Abbreviations}

\author{
PHASe $=$ Physical Health Attitude Scale \\ EFA $=$ exploratory factor analysis \\ CFA = confirmatory factor analysis
}

RMSEA = root-mean-square error of approximation

SRMR = standardised root-mean-square residual 
$\mathrm{CFI}=$ comparative fit index

TLI = Tucker-Lewis index

$\mathrm{CR}=$ composite reliability

\section{Declarations}

\section{Ethics approval and consent to participate}

The study has been performed in accordance with the Declaration of Helsinki and has been approved the Institutional Review Board (IRB) of Tri-Service General Hospital approved the study (TSGHIRB No.: 1-108-05-092). All participants provided written consent prior to data collection, and participants' anonymity and confidentiality were guaranteed.

\section{Consent for publication}

Not applicable

\section{Availability of data and materials}

The datasets generated during and analysed during the current study are available from the corresponding author on reasonable request.

\section{Competing interests}

The authors declare that they have no competing interests.

\section{Funding}

The study was supported by grants from the Ministry of Science and Technology, Taiwan (MOST-108-2314-B-016-055). The funders were not involved in the study design, data collection, data analysis and interpretation, writing of the manuscript, or the decision to submit this article for publication.

\section{Authors' contributions}

WT, HF, CL, YC and MH made substantial contributions to conception, design, acquisition of data, or analysis and interpretation of data. WT involved in drafting the manuscript. HF, CL, YC and $\mathrm{MH}$ revised the draft critically for important intellectual content. All authors read and approved the final manuscript.

\section{Acknowledgements}

We would like to thank all participants for their involvement in this study and Ms. Nien-Ting Kuo for her help during the research process.

\section{References}

1. Bressington, D., Badnapurkar, A., Inoue, S., Ma, H. Y., Chien, W. T., Nelson, D., \& Gray, R. (2018). Physical health care for people with severe mental illness: the attitudes, practices, and training needs of nurses in three Asian countries. International Journal of Environmental Research and Public Health, 15(2), 343. doi:10.3390/ijerph15020343

2. Chee, G. L., Wynaden, D., \& Heslop, K. (2018). The provision of physical health care by nurses to young people with first episode psychosis: A crosssectional study. Journal of Psychiatric Mental Health Nursing, 25(7), 411-422. doi:10.1111/jpm.12487

3. Chen, I. H., Huang, C.-R., \& Politzer-Ahles, S. (2018). Determining the types of contrasts: The influences of prosody on pragmatic inferences. Frontiers in Psychology, 9, 2110-2110. doi:10.3389/fpsyg.2018.02110

4. Chen, Y. H., Lin, H. C., \& Lin, H. C. (2011). Poor clinical outcomes among pneumonia patients with schizophrenia. Schizophrenia Bulletin, 37(5), 10881094. doi:10.1093/schbul/sbq019

5. Cohen, J. (1988). Statistical power analysis for the behavioral sciences (2nd ed.). Hillsdale, NJ: L. Erlbaum Associates.

6. De Hert, M., Correll, C. U., Bobes, J., Cetkovich-Bakmas, M., Cohen, D., Asai, I.,.. . Leucht, S. (2011). Physical illness in patients with severe mental disorders. I. Prevalence, impact of medications and disparities in health care. World Psychiatry, 10(1), 52-77. doi: 10.1002/j.20515545.2011.tb00014.x

7. de Mooij, L. D., Kikkert, M., Theunissen, J., Beekman, A. T. F., de Haan, L., Duurkoop, P.,.. . Dekker, J. J. M. (2019). Dying too soon: Excess mortality in severe mental illness. Frontiers in Psychiatry, 10, 855. doi:10.3389/fpsyt.2019.00855

8. DeVellis, R. F. (2017). Scale development: Theory and applications (4th ed.). Los Angeles, CA: Sage.

9. Dickens, G. L., Ion, R., Waters, C., Atlantis, E., \& Everett, B. (2019). Mental health nurses' attitudes, experience, and knowledge regarding routine physical healthcare: Systematic, integrative review of studies involving 7,549 nurses working in mental health settings. BMC Nursing, $18(1), 16$.

doi:10.1186/s12912-019-0339-x

10. Eagly, A. H., \& Chaiken, S. (1993). The psychology of attitudes. Fort Worth, TX: Harcourt Brace Jovanovich College Publishers. 
11. Fabrigar, L. R., Wegener, D. T., MacCallum, R. C., \& Strahan, E. J. (1999). Evaluating the use of exploratory factor analysis in psychological research. Psychological Methods, 4(3), 272-299. doi:10.1037/1082-989X.4.3.272

12. Ganiah, A. N., Al-Hussami, M., \& Alhadidi, M. M. B. (2017). Mental health nurses attitudes and practice toward physical health care in Jordan. Community Mental Health Journal, 53(6), 725-735. doi:10.1007/s10597-017-0143-6

13. Giandinoto, J. A., \& Edward, K. L. (2014). Challenges in acute care of people with co-morbid mental illness. British Journal of Nursing, 23(13), 728732. doi:10.12968/bjon.2014.23.13.728

14. Gray, R., \& Brown, E. (2017). What does mental health nursing contribute to improving the physical health of service users with severe mental illness? A thematic analysis. International Journal of Mental Health Nursing, 26(1), 32-40. doi:10.1111/inm.12296

15. Hair, J. F. (2010). Multivariate data analysis (7th ed.). Upper Saddle River, NJ: Prentice Hall.

16. Happell, B., Platania-Phung, C., \& Scott, D. (2014). What determines whether nurses provide physical health care to consumers with serious mental illness? Archives of Psychiatric Nursing, 28(2), 87-93. doi:10.1016/j.apnu.2013.11.001

17. Health Promotion Administration, Ministry of Health and Welfare, Taiwan (ROC) (2019, October). Taiwan tobacco control annual report 2019. Retrieved from https://www.hpa.gov.tw/Pages/List.aspx?nodeid=1069

18. Hjorthøj, C., Stürup, A. E., McGrath, J. J., \& Nordentoft, M. (2017). Years of potential life lost and life expectancy in schizophrenia: A systematic review and meta-analysis. Lancet Psychiatry, 4(4), 295-301. doi:10.1016/s2215-0366(17)30078-0

19. Hu, L., \& Bentler, P. M. (1999). Cutoff criteria for fit indexes in covariance structure analysis: Conventional criteria versus new alternatives. Structural Equation Modeling, 6(1), 1-55. doi:10.1080/10705519909540118

20. Jones, P. S., Lee, J. W., Phillips, L. R., Zhang, X. E., \& Jaceldo, K. B. (2001). An adaptation of Brislin's translation model for cross-cultural research. Nursing Research, 50(5), 300-304. doi:10.1097/00006199-200109000-00008

21. Major, B., Dovidio, J. F., \& Link, B. G. (2018). The Oxford handbook of stigma, discrimination, and health. New York: Oxford University Press.

22. Ministry of Health and Welfare, Taiwan (ROC) (2021, July 23). Mental health systems and resources. Retrieved from https://dep.mohw.gov.tw/DOS/cp-5221-62356-113.html

23. Nunnally, J. C., \& Bernstein, I. H. (1994). Psychometric theory (3rd ed.). New York: McGraw-Hill.

24. National Institute of Mental Health (2017, November 30). Mental illness. Retrieved from https://www.nimh.nih.gov/health/statistics/mentalillness.shtml

25. Ozaslan, Z., Bilgin, H., Uysal Yalcin, S., \& Haddad, M. (2020). Initial psychometric evaluation of the physical health attitude scale and a survey of mental health nurses. Journal of Psychiatric Mental Health Nursing, 27(1), 62-76. doi:10.1111/.jpm.12553

26. Pan, Y. J., Yeh, L. L., Chan, H. Y., \& Chang, C. K. (2017). Transformation of excess mortality in people with schizophrenia and bipolar disorder in Taiwan. Psychological Medicine, 47(14), 2483-2493. https://doi.org/10.1017/S0033291717001040

27. Polit, D. F., \& Beck, C. T. (2018). Essentials of nursing research: Appraising evidence for nursing practice (9th ed.). Philadelphia, PA: Wolters Kluwer Health.

28. Price, B. (2015). Understanding attitudes and their effects on nursing practice. Nursing Standard, 30(15), 50-57. doi:10.7748/ns.30.15.50.s51

29. Prudon, P. (2015). Confirmatory factor analysis as a tool in research using questionnaires: A critique. Comprehensive Psychology, 4 , https://doi.org/10.2466/03.CP.4.10

30. Robson, D., \& Haddad, M. (2012). Mental health nurses' attitudes toward the physical health care of people with severe and enduring mental illness: The development of a measurement tool. International Journal of Nursing Studies, 49(1), 72-83. doi:10.1016/j.ijnurstu.2011.07.011

31. Robson, D., Haddad, M., Gray, R., \& Gournay, K. (2013). Mental health nursing and physical health care: a cross-sectional study of nurses' attitudes, practice, and perceived training needs for the physical health care of people with severe mental illness. International Journal of Mental Health Nursing, 22(5), 409-417. doi:10.1111/j.1447-0349.2012.00883.x

32. Siren, A., Cleverley, K., Strudwick, G., \& Brennenstuhl, S. (2018). Modification and initial psychometric evaluation of the physical health attitude scale for use in the Canadian mental health and addictions context. Issues in Mental Health Nursing, 39(11), 946-953.

doi:10.1080/01612840.2018.1475523

33. Tseng, K. J., Liou, T. H., \& Chiu, H. W. (2012). Development of a computer-aided clinical patient education system to provide appropriate individual nursing care for psychiatric patients. Journal of Medical Systems, 36(3), 1373-1379. https://doi.org/10.1007/s10916-010-9599-4

34. Walker, E. R., McGee, R. E., \& Druss, B. G. (2015). Mortality in mental disorders and global disease burden implications: A systematic review and metaanalysis. JAMA Psychiatry, 72(4), 334-341. doi:10.1001/jamapsychiatry.2014.2502

35. Wang, J. Y., Chang, C. C., Lee, M. C., \& Li, Y. J. (2020). Identification of psychiatric patients with high mortality and low medical utilization: A population-based propensity score-matched analysis. BMC Health Service Research, 20(1), 230. doi:10.1186/s12913-020-05089-6

36. World Health Organization (2010, November). Global recommendations on physical activity for health. Geneva, Switzerland: World Health Organization. Retrieved from https://www.who.int/publications/i/item/9789241599979

\section{Figures}




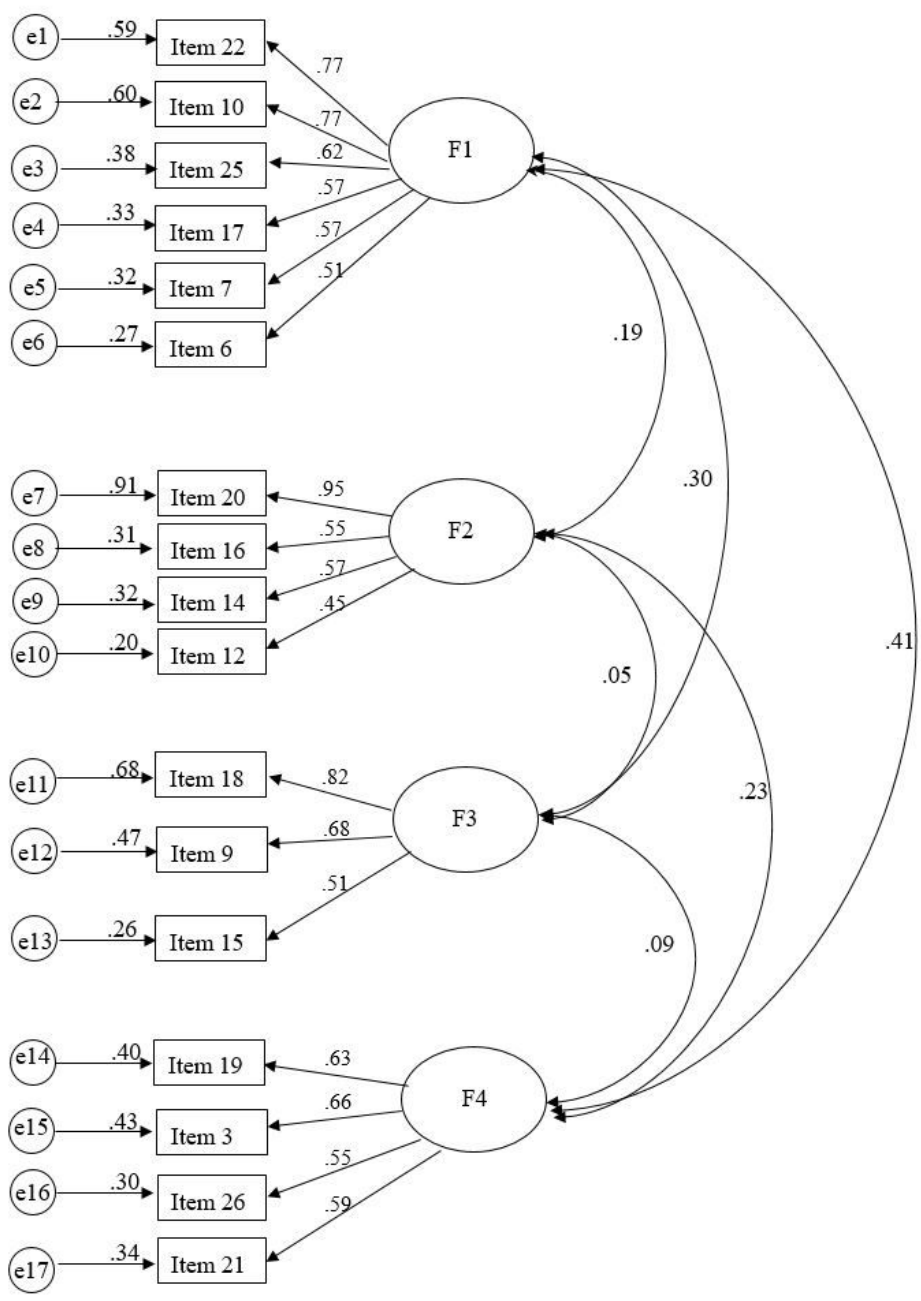

\section{Figure 1}

Confirmatory factor analysis of the Chinese version of the PHASe. Factor $1=$ Involvement in physical healthcare (six items), Factor $2=$ Attitude to smoking (four items), Factor 3 = Perception of obstacles to engagement in physical healthcare (three items), and Factor $4=$ Confidence in physical healthcare practice (four items). 